\title{
Right Sided Bochdalek Hernia in Adult: A Case Report and Review of Literature
}

\author{
Sharma BN 1 , Gupta $D^{2}$ \\ ${ }^{1}$ Department of Radiodiagnosis, Bheri Zonal Hospital, Nepalgunj \\ ${ }^{2}$ Department of Urology, Nepalgunj Medical College, Nepalgunj
}

Received: December 10, 2017

Accepted: February 10, 2018

Published: June 30, 2018

Cite this paper:

Sharma BN, Gupta D. Right Sided Bochdalek Hernia in Adult: A Case Report and Review of Literature. Nepalese Journal of Radiology 2018;8(11):44-47.http://dx.doi.org/10.3126/njr.v8i1.20457

\begin{abstract}
Bochdalek hernia is the most common congenital diaphragmatic hernia that typically presents in childhood. However, right sided diaphragmatic hernia is relatively rare. We review the case of 21 years old female with incidentally detected congenital diaphragmatic hernia on the right side. There are fewer than 20 cases of right sided diaphragmatic hernia reported in adults in literature.
\end{abstract}

Keywords: Adult; Computed Tomography; Hernia, Diaphragmatic, Congenital

\section{INTRODUCTION}

Correspondence to: Dr. Bishwanath Sharma Department of Radiodiagnosis Bheri Zonal Hospital, Nepalgunj Email: bishwanath233@gmail.com
Bochdalek hernia is the most common congenital hernia \&involves the posterior defect in diaphragm caused by defective fusion of the pleuroperitoneal membrane. The majority presents during neonatal life. It is a common cause of respiratory distress in newborn. In adults, these are usually asymptomatic and incidentally detected on chest $\mathrm{x}$ ray or computed tomography. Here, we present a case of 21 years old female with incidentally detected diaphragmatic hernia. Our aim is to present a rare case of diaphragmatic hernia in adult and to emphasize the significant role of imaging for the diagnosis of this condition. There are fewer than 100 cases of Bochdalek hernia reported in adults and fewer than 20 of those cases involving right side. ${ }^{1}$ 


\section{CASE REPORT}

A 21 year old female presented with pain in left lumbar region. She had been diagnosed with left nephrolithiasis and scheduled for surgery. She was not taking any medication. There was no history of abdominal or thoracic trauma. There was no evidence of any abnormality on physical examination.Ultrasound of the abdomen revealed left nephrolithiasis. Preoperative chest $\mathrm{X}$ ray revealed some form of unusual opacity in right lower zone and referred to radiologist for review. We reviewed chest $x$ ray of the patient. Chest $X$ ray findings were subtle. Subtle opacity was noted on medial aspect of right lower zone. Air fluid level was noted on the inferior aspect of right lower zone. Subtle added density was noted on posteroinferior aspect on lateral view (Fig 1). Chest xray findings were suspicious of diaphragmatic hernia. So, further evaluation by CT Scan was done.

CT scan revealed defect on the diaphragm on midline and right posteromedial aspect. There was evidence of herniation of stomach and part of right transverse colon including mesenteric fat in right hemithorax (Fig 2 \& Fig 3). Patient was counselled about the possible complications of diaphragmatic hernia. Since the patient had colicky pain in the left lumbar region, she underwent percutaneous nephrolithotomy (PCNL) for left nephrolithiasis. Postoperative course was uneventful. Since there were no symptoms related to diaphragmatic hernia, the patient was not convinced for surgery. After repeated counseling explaining the possible complications that might occur, if left untreated, patient was convinced for surgery later. Patient was discharged at this time keeping all the contact details for follow up counseling.

\section{DISCUSSION}

Congenital diaphragmatic hernias are of two types. Bochdalek hernia is the most common congenital hernia and involves the posterior defects in diaphragm caused by defective fusion of pleuroperitoneal membranes. Morgagni hernias are seen in adults and are mostly asymptomatic. It is caused by failure of fusion between the fibrotendinous elements of the sternal part of the diaphragm and those of the costal part. Most Bochdalek hernias are diagnosed in children who present with acute pulmonary symptoms. ${ }^{2}$ Bochdalek hernias on right side are extremely rare because the right pleuroperitoneal canal closes earlier and the liver buttresses the right hemidiaphragm. Even on the right sided bochdalek hernia, herniation of stomach on right side as in our case is extremely rare. We have found only one case with herniated stomach on right side after reviewing the available literature. ${ }^{3}$ In

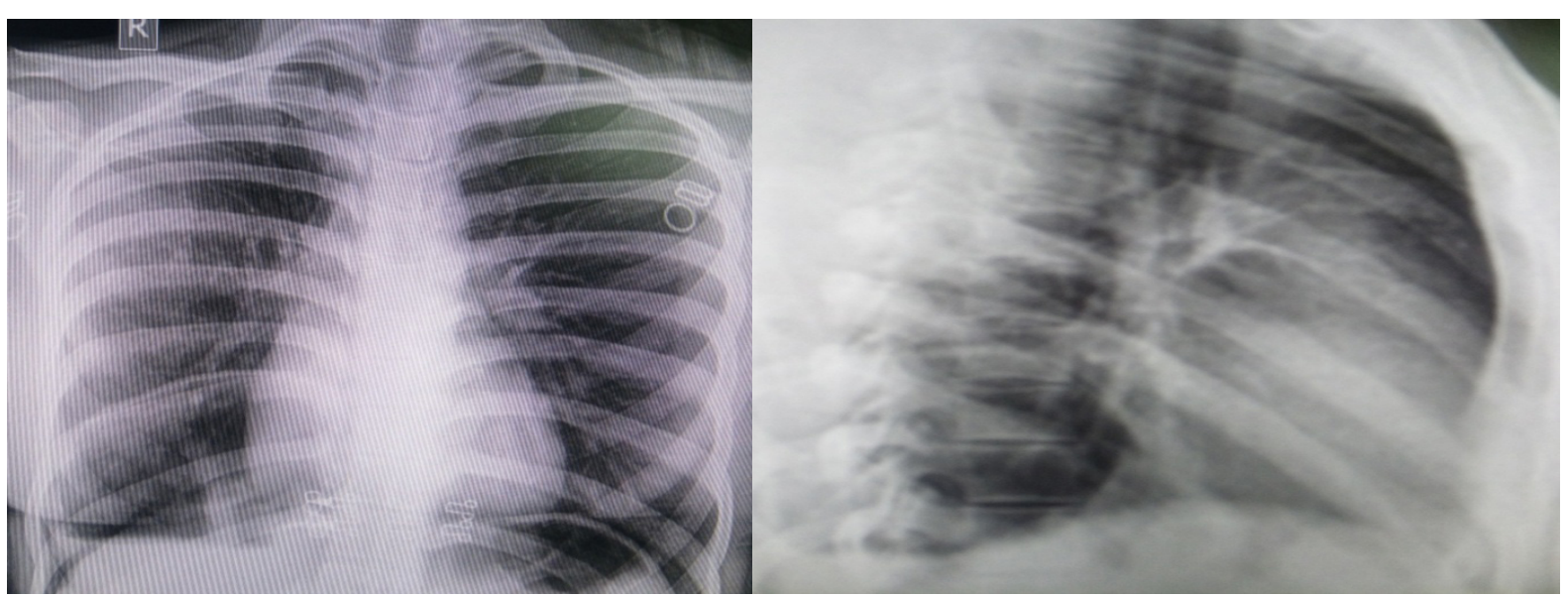

Figure 1: Chest X ray PA and Lateral views showing subtle opacity in the medial aspect of right lower zone with air fluid level. 


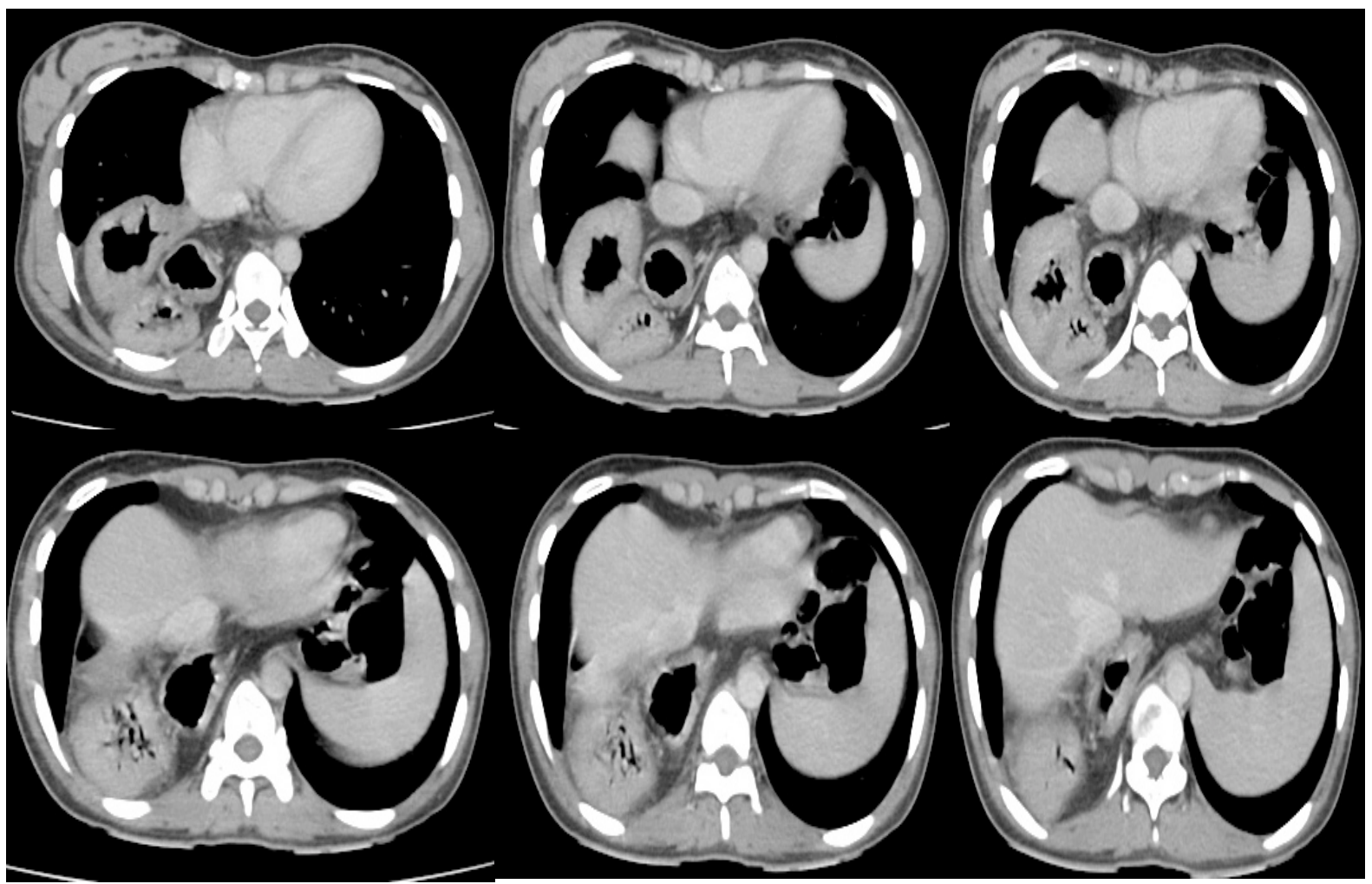

Figure 2: CT scan axial views showing herniation of stomach and colon within right hemithorax.

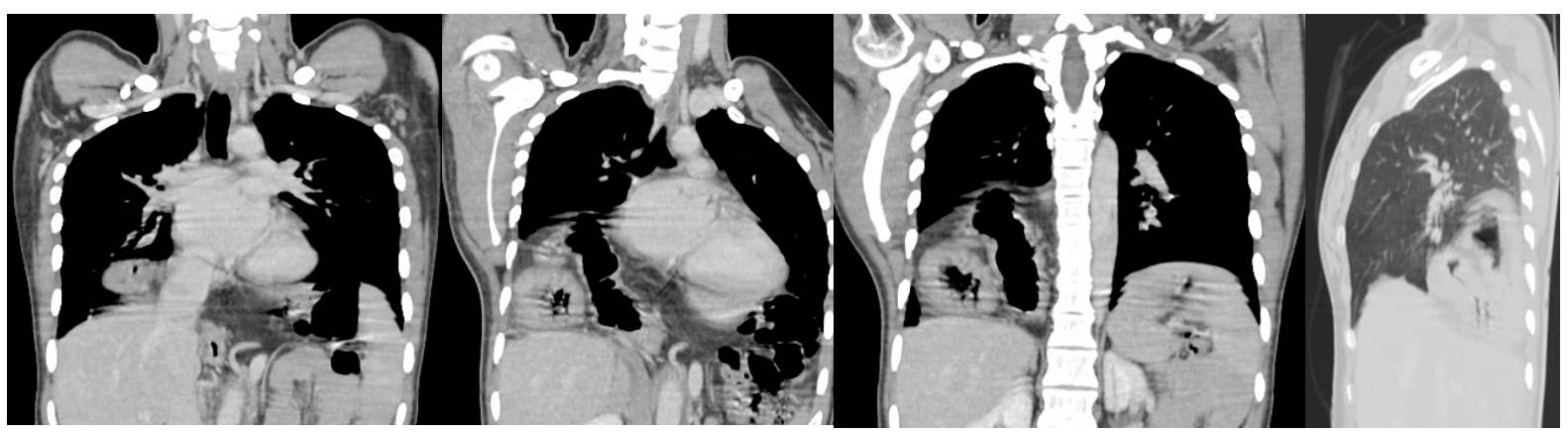

Figure 3: Coronal and saggital reconstruction of CT showing herniation of colon and stomach within the right chest.

contrast to the acute presentation by infants with these hernias, most adults present with chronic symptoms such as chronic dyspnea, chest pain and pleural effusion. Recurrent abdominal pain, postprandial fullness and vomiting are the most common abdominal symptoms in adults. ${ }^{4}$ Others will present with serious complications associated with strangulation of herniated viscus especially when the diagnosis has been missed or treatment delayed. However, some patients are asymptomatic and the disorder is unexpectedly detected on chest X-ray as in our case. Gastric volvulus is one of the rare but recognized complication of Bochdalek hernia.

Several imaging modalities are used to detect diaphragmatic hernias, including chest $\mathrm{x}$ ray (sometimes after nasogastric tube placement), fluoroscopy, barium studies, CT and magnetic resonance imaging (MRI).Antenatal diagnosis of congenital diaphragmatic hernia on ultrasound is suspected when the fetal heart is displaced either by an intrathoracic solid mass (liver, kidney) or by fluid filled 
structure (stomach, bowel) with decreased abdominal circumference. ${ }^{5}$ The gold standard for diagnosis is multidetector CT (MDCT). On CT, the diagnosis of Bochdakek hernia can be made when there is discontinuity of diaphragm with herniation of abdominal contents into thorax. ${ }^{6}$ When small, a soft tissue or fatty mass is seen abutting the posteromedial aspect of diaphragm. With the advent of CT, however, many small asymptomatic defects are being detected in adults. These hernias present on the lateral chest film as small bulge centred anterior to posterior costophrenic angle. Chest radiographs have a sensitivity of greater than $70 \%$ and usually demonstrate air fluid levels. It must be noted that normal chest X-ray does not exclude Bochdalek hernia. ${ }^{1,7,8}$

\section{CONCLUSION}

Adult right sided Bochdalek hernia is a rare condition. There is significant role of MDCT in the diagnosis of this condition. Patient may be asymptomatic. The condition should be recognized to treat appropriately to avoid possible complications.

\section{CONFLICT OF INTEREST}

None

\section{SOURCE OF FUNDING}

None

\section{REFERENCES}

1. Rout S, Foo FJ, Hayden JD, Guthrie A, Smith AM. Right-sided Bochdalek hernia obstructing in an adult: case report and review of the literature. Hernia 2007;11: 359-362. https://doi.org/10.1007/s10029-0070188-5

2. Kocakusak A, Arikan S, Senturk O, Ycel AF. Bochdalek's hernia in an adult with colon necrosis. Hernia 2005;9:284-287. https://doi.org/10.1007/s10029-004-0302-x
3. Kurt A, Yazıcıoğlu KR, İpek A, Tosun Ö, Coşkun M. Right sided diaphragmatic hernia in an adult with no historyof trauma: Unusual CT findings. Eur J Gen Med 2004;1(3):55-57. https://doi.org/10.29333/ejgm/82213

4. Kanazawa A, Yoshioka Y, Inoi O, Murase $\mathrm{J}$, Kinoshita $\mathrm{H}$. Acute respiratory failure caused by an incarcerated right-sided adult Bochdalek hernia: report of a case. Surg Today 2002; 32: 812-815. https://doi.org/10.1007/s005950200156

5. Comstock $\mathrm{CH}$. The Antenatal diagnosis of diaphragmatic abnormalities. $J$ ultrasound Med 1986;5:391-396. https://doi.org/10.7863/jum.1986.5.7.391

6. Killen KL, Mirvis SE, Shanmuganathan K. Helical CT of Diaphragmatic Rupture Caused by Blunt Trauma. AJR Am $J$ Roentgenol 1999;173:1611-1616. https://doi.org/10.2214/ ajr.173.6.10584809

7. Esmer D, Alvarez-Tostado J, Alfaro A, Carmona R, Salas M. Thoracoscopic and laparoscopic repair of complicated Bochdalek hernia in adult. Hernia 2008;12:307-309. https://doi.org/10.1007/s10029-0070293-5

8. Losanoff JE, Sauter ER. Congenital posterolateral diaphragmatic hernia in an adult. Hernia 2004;8:83-85. https://doi.org/10.1007/s10029-003$\underline{0166-5}$ 